\title{
A New Measure of Workplace Innovation
}

\author{
Fraenze Kibowski \\ Tom Baguley \\ Peter Totterdill \\ Maria Karanika-Murray
}

\begin{abstract}
Despite the popularity of Workplace Innovation (WI) and its demonstrable utility for supporting both organisational productivity and employee well-being, there is at present no reliable and valid measure of WI practices for use in research and workplace settings. The aim of this paper is to present the development of a measure of WI climate. The study involved 855 individuals across all levels of three organisations, and a survey of WI practices that was based on four underlying elements: jobs and teams; organisational structures, management and procedures; employee-driven improvement and innovation; and co-created leadership and employee voice. The original list of items was developed in consultation with employers and practitioners. WI was assessed as climate perceptions. A series of analyses were undertaken on the measure, demonstrating good psychometric properties, including consistency of the factor structure, internal reliability, construct validity, and criterion validity. Support for reliability and validity of the new 19-item measure with four elements is presented. Employees who experienced the four elements of WI climate more positively also enjoyed greater work engagement and job satisfaction, outlining criterion validity of the new measure. The availability of a rigorous and reliable measure of WI climate offers a tool for practitioners and researchers tasked with communicating and promoting WI in diverse workplace settings and with diverse groups of stakeholders. We hope that this new measure of WI will stimulate further research on the role of WI in promoting healthy and productive workplaces.
\end{abstract}

Keywords: workplace innovation, measurement validation, work engagement, job satisfaction 


\section{Measuring Workplace Innovation Practices}

Workplace innovation (WI) is an area of growing international interest in both government and academia (e.g., Karanika-Murray \& Oeij 2017a, 2017b; Gkiontsi \& Karanika-Murray 2015; Eeckelaert, Dhondt, Oeij, Pot, Nicolescu, Trifu, \& Webster 2012; Exton \& Totterdill 2009; OECD 2010; Pot, Totterdill \& Dhondt 2016; Totterdill 2015) reflecting growing policy concerns with skills utilisation, productivity, and competitiveness on the one hand, and with workplace health and well-being, on the other. It is this potential for convergence, as opposed to trade-off, between improved performance and enhanced quality of working life that lies at the heart of WI (Ramstad 2009, 2014; Dhondt, van Gramberen, Keuken, Pot, Totterdill \& Vaas 2011). A growing number of European countries have been developing policy interventions and programme to support companies and their employees in transforming traditional work practices through WI, typically seeking to achieve a convergence between enhanced business performance and quality of working life (Totterdill et al.,2015). At EU policy level the concept of 'social innovation' at work or 'workplace innovation' is an increasingly important pillar in achieving the EU2020 Strategy goals of "smart and inclusive growth" at the organisational level (EESC 2011).

Despite the importance of WI for promoting sustainable employment, well-being, and productivity, there has been limited progress in developing measures of WI, and for valid reasons: first, it is multidimensional as it comprises a range of dimensions or elements, and second, it is as complex to operationalise as to implement. The broad range of WI indicators that have been used makes it difficult to integrate research findings. Nevertheless, as with any area of practice, accurate measurement is important for evaluating WI efforts.

In this paper we present the results of a study designed to validate a measure of WI practices, which were assessed as the participants' climate perceptions. In order to examine the predictive validity of the measure, we also demonstrate how WI can support work engagement and job satisfaction, as indicators of enhanced quality of working life. Next, we describe WI in more detail before we discuss how WI practices can impact work engagement and job satisfaction.

\section{Workplace Innovation Practices}

WI is a broad concept that overlaps with organisational and process innovation and draws from a number of disciplines such as HRM, innovation management, and organisational development (Karanika-Murray \& Oeij 2017a, 2017b). We adopt the following working definition of WI: "workplace innovations are strategically induced and participatory adopted changes in an organisation's practice of managing, organising and deploying human and non-human resources that lead to simultaneously improved organisational performance and improved quality of working life" (p. 6, Eeckelaert et al. 2012; also see Oeij, Rus \& Pot 2017; Pot, Dhondt \& Oeij 2012; Ramstad 2009). Similarly, Oeij, Žiauberytė-Jakštienè, Dhondt, Corral, Totterdill and Preenen (2015) define WI as "developed and implemented practice or combination of practices that structurally (structure orientation or a focus on division of labour) and/or culturally (culture orientation or a focus on empowerment) enable employees to participate in organisational change and renewal to improve quality of working life and organisational performance" (p. 8).

The basic premise for WI is that neither set of policy goals (skills utilisation, productivity and competitiveness, on the one hand, and workplace health and well-being, on the other) can be fully achieved by traditional policy levers such as macro-economic manipulation, skills supply, or health and safety regulation (UKCES 2009). Likewise, at enterprise level there is only limited return on investment in technology (Brödner \& Latniak 2002) or skills development (CEDEFOP 2015) when, for example, the tacit knowledge of employees, skills utilisation and workforce creativity are overlooked (UKCES 2009). 
The interplay between workplace practices and participative process is central for WI and its dual aim of promoting productivity and quality of working life. WI involves the implementation of practices that are adopted with the aim to induce change towards a defined end and encourage learning from diverse sources (Pot, Totterdill \& Dhondt 2016) but is also an inherently social process, which relies on building skills and competence through participation (Totterdill 2015). Rather than attempting to develop a comprehensive measure of these different aspects of WI (practices and processes) and its dual outcomes (productivity and quality of working life), we focus on the practices that can support WI and assess them as the employees' perceptions of workplace climate for WI.

\section{Four Dimensions of WI Practices}

A range of workplace practices have been implicated in successfully developing WI in organizations. WI is fuelled by open dialogue, knowledge sharing, experimentation, and learning in which diverse stakeholders including employees, trade unions, managers, and customers are given a voice in the creation of new models of collaboration and new social relationships (Dhondt, van Gramberen, Keuken, Pot, Totterdill, \& Vaas 2011; Totterdill 2015). WI seeks to build bridges between the strategic knowledge of the leaders, the operational tacit knowledge of frontline employees, and the organisational design knowledge of experts. It seeks to engage all stakeholders in dialogue in which the force of the better argument prevails (Gustavsen 1992).

WI can take diverse forms, according to a review of 120 case studies across ten European countries (Totterdill, Dhondt \& Milsome 2002), but "above all [it] is characterised by the search for 'win-win' solutions: enhancing organisational performance and job satisfaction by developing and using employee competencies and creative potential to the maximum extent" (p. 3, Totterdill et al. 2002). Totterdill et al. (2002) discussed that these factors in the work environment include empowering job design; selforganised team working; structured opportunities for reflection, learning and improvement; high involvement innovation practices; the encouragement of entrepreneurial behaviour at all levels of the organisation; and employee representation in strategic decision-making. Similarly, the Netherlands Centre for Social Innovation (NCSI) specifies work organisation, labour relations, and network relations as the key drivers of organisational performance and utilisation of human resources. In addition, the Netherlands Employer Work Survey (NEWS) uses a construct of WI that includes the following: strategic orientation, flexible work, smart organising, and product-market improvement (Eeckelaert et al. 2012).

Based on a review of over one hundred articles and a similar number of case studies, the broad range of practices relevant to WI can be summarized into four groups of practices (Totterdill 2015) or four elements: (1) jobs and teams (organisation), (2) organisational structures, management and procedures (structure), (3) employee-driven improvement and innovation (learning), and (4) co-created leadership and employee voice (partnership). In combination, these ingredients enable convergence between high levels of economic performance and high quality of working life. The combination of WI practices at every level creates a tangible effect in workplaces that is often described in terms of improved engagement and a cultural transformation (so-called fifth element; Totterdill 2015) with resulting benefits for performance and working life, which can only take place when the other four elements combine.

Because of the importance of the interdependence between the four elements, it is also important that WI is examined in a comprehensive way, since "a reduction of WI to fragmented practices or general questions on organizational change is likely to lead to neglecting the specific characteristics and potential of WI" (EIS report 2014). Policies and practices that are internally consistent and combine different forms of representative and direct participation, can help to achieve superior outcomes for organizations and their employees compared to individual measures (Lado \& Wilson 1994; Huselid, Jackson, \& Schuler 1997; Teague 2005). Studies of failed WI initiatives show that partial change can undermine the introduction of empowering working practices (Business Decisions Ltd 2002). More 
information on the framework can be found at the EUWIN Knowledge Bank (http://uk.ukwon.eu/thefifth-element-new).

Next, we outline each of the four groups of WI practices or elements. We describe these four elements as WI-enabling practices. For additional information and detail on these practices the reader is referred to Totterdill (2015).

\section{The First Element of WI Practices: Jobs and Teams (Organisation)}

The evidence for the benefits of a range of job design features for "simultaneously improved organisational performance and improved quality of working life" (p. 6, Eeckelaert et al. 2012) is strong and consistent (Oeij, Rus, \& Pot 2017; Pot, Dhondt \& Oeij 2012; Ramstad 2009). Building workplaces in which employees can develop and deploy their competencies and achieve their potential begins with job design. A number of features ought to be present, in tandem, according to standards of job design developed in The Netherlands in the 1990s. These standards include: the ability to assume responsibility for day-to-day decisions about work through co-operation or communication with others; the existence of systematic opportunities for problem-solving through horizontal contact with peers; the ability to adapt work execution to changing demands, circumstances or opportunities; demonstrable opportunities for analysis, problem-solving and innovation; frequent horizontal and vertical contact to support problem-solving, learning and innovation; and distributed intelligence throughout the organization ensuring that knowledge and expertise are widely shared or readily accessible by employees (Karasek \& Theorell 1991; Shantz, Alfes, K., Truss, C., \& Soane 2013). The job design literature provides support for the benefits of these features on managing the job demands, avoiding psychological stress and disengagement associated with repetitive and disempowering work (Bakker \& Demerouti 2007; Morgeson \& Humphrey 2006; Shantz et al. 2013; Truss et al. 2013), engaging better and being better motivated (Christian et al. 2011; Fried \& Ferris 1987; Hackman \& Oldham 1980; Humphrey, Nahrgang, \& Morgeson 2007), and acquiring transferable skills, increasing adaptability and resilience within the organisation and employability outside it (CEDEFOP 2015).

Effective job design must develop in synchrony with team working, one of the defining characteristics of WI, with roots in European thinking about management and organisation dating back to the work of the Tavistock Institute in the 1940s and 50s. Empowered and self-managed teams are more productive and provide better customer service (Totterdill, Dhondt \& Milsome 2002; West 2012). A survey of European 6000 workplaces showed that amongst firms which implemented semiautonomous teams, $68 \%$ reported reductions in costs, $87 \%$ reduced throughput times, $98 \%$ improved products and services, and $85 \%$ increased sales (Walker 1997).

However, while team working may refer to a general "sense of community", or a limited enlargement of jobs to enhance organisational flexibility, empowered team working will involve a radical reappraisal of jobs, systems and procedures throughout the whole organisation (West \& Lyubovnikova 2012). All team members must have the potential for a high level of reflexivity unconstrained by internal demarcations and privileges (Gustavsen 1992).

Teams in which the specific knowledge and expertise of each team member are valued and make a tangible contribution to product and WI meet important criteria for convergence between enhanced productivity and enhanced quality of working life. Yet convergence is only possible and sustainable when structures, systems, industrial relations and leadership are fully aligned with the empowerment of employees in their day-to-day jobs (Boxall \& Purcell 2003; Buchanan \& Preston 1992; Teague 2005). These interdependencies are explored further in the other three elements. 
The Second Element: Organisational Structures, Management and Procedures (Structure)

Organisational walls and ceilings that allocate people to departments, divisions, grades and professions can create silos that put barriers in the way of doing a good job. Different groups within an organisation should intertwine in ways that help everyone understand other people's jobs, professions, specialisms, priorities, problems and vision. Systems and procedures that govern decision-making, resource allocation and standard operating procedures must also be aligned with commitment to empowerment and trust. Truly innovative workplaces demonstrate a consistent approach through corporate policy from reward systems and performance appraisal to flexible working and budget devolution.

\section{The Third Element: Employee-Driven Improvement and Innovation (Learning)}

Research and technology-led activity accounts for only $25 \%$ of innovation; the remaining $75 \%$ of successful innovation is generated by changing managerial, organisational and work practices (Jansen, Volberda, \& van den Bosch 2009; Volberda et al. 2011). Such innovation is strongly associated with "active work situations": workplaces and jobs in which workers have sufficient autonomy to control their work demands coupled to discretionary capacity for learning and problem-solving (Parent-Thirion, Vermeylen, \& Houten 2012; Tidd \& Bessant 2009).

\section{The Fourth Element: Co-Created Leadership and Employee Voice (Partnership)}

Partnership between management, employees and trade unions can take many forms but always requires openness, transparency and two-way communication. Representative partnership structures (such as works councils and management-union partnership forums) on their own may have little direct impact on performance or quality of working life but they can exert a positive influence on the development of activities and practices that do so. Partnership arrangements alongside the previous three Elements leads to improved information sharing, enhanced trust and reduced resistance to change.

\section{Benefits of Workplace Innovation Practices}

The benefits of WI have been documented for both individual employees and organisations and in a range of organisational and national contexts. WI has been linked to improved individual level outcomes such as indices of quality of working life (Pot 2011) and improved organisational performance such as reduced absenteeism, enhanced safety performance and safety culture, and better working conditions (Eeckelaert et al. 2012). Furthermore, Van Der Hauw and colleagues (2009) reported higher productivity as a result of implementing WI. Benefits of specific WI practices have also been reported, relating to enhancing the likelihood of securing a full return on investments in training and technology as a result of improvements in performance, innovation, and quality of working life (Totterdill et al. 2002). The combined and cumulative impact of WI practices is likely to enhance motivation, involvement, fulfilment, resilience, ownership and pride in work, all of which characterise high engagement with day-to-day work (MacLeod \& Clarke 2009). WI has also been presented as a timely and effective response to the economic and demographic challenges brought about by the ageing workforce (Gkiontsi \& Karanika-Murray 2015).

For the purposes of developing and validating the measure of WI practices, we focus on two indicators of quality of working life as outcomes of WI practices: work engagement and job satisfaction. Employee engagement and the development of participative approaches is at the heart of WI. "It is important to see Workplace Innovation not as an end state but as a dynamic, reflexive process in which all stakeholders are continually engaged in reflecting on, learning about and transforming work processes and employment practices in response to both internal and external drivers" (Dortmund/Brussels Position Paper on Workplace Innovation 2012, pp. 2-3). Workplace practices that enable WI by supporting better work organisation can enrich jobs and reduce intensification or labour and provide 
the foundations for individuals to achieve a balance between demands and control. Furthermore, WI practices that focus on developing structure and systems can support good working methods and relationships. Similarly, WI practices that support learning and reflection can support competence development, continuous improvement, product and service innovation and efficiency gains (Boud et al. 1985). Finally, WI practices that support the culture and practice of workplace partnership strengthen "employee voice", helping to close the gap between tacit and strategic knowledge within an organisation, enhancing the quality of decision making and implementation while improving employment relations (Purcell \& Georgiadis 2007). Together, we can expect that WI practices bolster perceptions of work. Therefore, we can hypothesise that WI practices will be positively linked to work engagement and job satisfaction.

\section{Method}

\section{Participants}

The overall sample of 855 participants was collected from 3 organizations: 162 participants from organisation A, 60 from organisation B, and 633 participants from organisation C. To develop and test the measure, the overall sample was divided into two: Sample 1 from organisations A and B (222 participants) and Sample 2 from organisation C (633 participants). The means and standard deviations of the overall sample are available on request from the first author.

\section{Measures}

Perceptions of WI practices were measured using a list of 24 items describing jobs and teams (organisation; items 1-6), organisational structures, management and procedures (structure; items 7-12), employee-driven improvement and innovation (learning; items 13- 17) and co-created leadership and employee voice (partnership; items 18-24). The labels in parentheses are used to identify factors during modelling (see Appendix 1), with items 6, 7, and 10 being reversescored. The item pool was developed in consultation with employers and practitioners to describe the four elements of WI practices and for reflection and a way to encourage consultation among stakeholders (see Totterdill et al. 2015). Since the WI practices are properties of the workplace, we used the referentshift consensus model (Chan 1998) and the respondents' organisation as the referent for the items, which describes the WI climate in the organisation. Specifically, participants were asked to indicate to what extent they agree with a number of statements regarding the current situation in their organisation on 5-point Likert-style scale ( 1 = "strongly disagree" to 5 = "strongly agree").

Work engagement was measured with the short version of the Utrecht Work Engagement Scale (Schaufeli, Bakker, \& Salanova 2006) which asks participants to indicate how they feel about their work on a 7-point rating scale ( $0=$ "never" to $6=$ "always/every day"). The measure consists of three sub-scales: vigour (e.g., "At my work, I feel bursting with energy"), dedication (e.g., "I am enthusiastic about my job"), and absorption in one's work (e.g., "I feel happy when I am working intensely"). Job satisfaction was measured by one item ("all in all, I am satisfied with my job"). Respondents were asked to indicate the extent to which they agreed with the statement. Demographic variables (age, gender, educational level, and relationship status) were also assessed.

\section{Statistical analyses}

In order to investigate the structural consistency of the four elements, a reliability analysis was performed on sample 1, comparing a one factor model with a 4-factor model. Badly performing items 
in terms of internal consistency were highlighted. Badly performing items were defined as items that had an unacceptable level of internal consistency raising Cronbach's alpha $(\alpha)$ value above 0.7 if item deleted. Second, exploratory factor analysis (EFA) was undertaken on sample 1 keeping in mind the identified badly performing items. Third, the competing models resulting from the reliability analyses and the EFA were compared as to their respective fit to the data using confirmatory factor analysis (CFA) on sample 2. Following Hu and Bentler (1999) fit was judged based on the statistics TLI, RMSEA and SRMR, with good fit suggested by TLI $\geq .95$, and values RMSEA $\leq .05$ or SRMR $\leq .08$. Finally, the criterion validity of the final measure was examined by running regression analyses with work engagement and work satisfaction as outcomes of WI. Analyses were carried out in Mplus (version 7.2; Muthén \& Muthén 1998-2014).

\section{Results}

\section{Descriptives of the item pool}

Skewness and excess kurtosis of the 24 items were within the range of -2 to +2 . Examination of interitem correlations indicated that item 4 was weakly correlated with all other items (the highest being 0.16 ) and was excluded. Items 21 and 22 were highly correlated, $r(221)=.822,95 \%$ CI $[.77, .86]$, suggesting the exclusion of one to increase parsimony and minimise the risk of multicollinearity. Based on their face validity, item 21 was excluded. Correlations between items 13 and 14, and items 18 and 19 were high $(.725,95 \%$ CI [.66, .78], and .712, 95\% CI [.64, .77], respectively) and these items were highlighted for potential exclusion. Finally, inspection of item 9 suggested it may relate to jobs and teams rather than organisational structures, management and procedures, which was further tested in the CFA models.

\section{Reliability analyses/item analysis}

The remaining 22 items (excluding items 4 and 21) had Cronbach's $\alpha=.929,95 \%$ CI [.91, .95], on 126 participants of sample 1 . Factor one (items $1-3,5,6$ ) achieved $\alpha=.62,95 \%$ CI $[.53, .70]$ nearing the cut-off of 0.7 suggested by Nunally (1978). Item 9 was included on the basis of better face validity with this factor, raising $\alpha$ to $.715,95 \%$ CI $[.65, .77]$. Elimination of item 6 raised $\alpha$ to $.739,95 \%$ CI $[.68$, $.80]$.

Factor two (items 7-12) had $\alpha=0.742,95 \%$ CI $[.68, .80]$. Excluding item 7 raised $\alpha$ to $0.780,95 \% \mathrm{CI}$ $[.73, .83]$ and excluding item 9 (to be moved to factor 1 ) placed $\alpha$ above the cut-off at .713, $95 \% \mathrm{CI}$ $[.65, .78]$.

Items 6 and 7 were highlighted for exclusion owing to them raising their respective factor's $\alpha$ value. Item analysis was carried out to assess their functioning as an item, and the facility index (the sum of all scores/number of participants should not equal 1 or 5) and frequency problems ( 2 or more response scales aggregate to less than $10 \%$ of answers) were also checked. While item 6 passed on both of these, item 7 performed badly. Item 7 scored 4.23 on the facility index, approaching the extreme point of the answering scale of 5. Furthermore, both the aggregation of participants answering as answer scale 1 and $2(7.4 \%)$ and 2 and $3(8.6 \%)$ fell below the cut off of $10 \%$. Therefore, the answer scale for item 7 is not discriminative. Most respondents used the upper two categories (for these items it meant that over $80 \%$ of participants disagree or strongly disagree that the flexibility employed by the organisation is harmful to employee's health). For this reason, item 7 was excluded.

For factor three (items 13-17) Cronbach's $\alpha$ was .894, 95\% CI [.87, .92]. Keeping in mind the earlier suggestion of items 13 and 14 having a high correlation with each other, alpha values much in excess of .8 indicate potential redundancy of the items of the scale (Bradley 2013). This was also relevant for 
the fourth factor (items 18-20 and 22-24) as it had a $\alpha=0.865,95 \%$ CI $[.86, .91]$ consistent with the high correlation between items 18 and 19 .

\section{Exploratory Factor Analysis}

An EFA with principal axis factoring was undertaken on sample 1 in order to examine the dimensionality of the remaining 21 items $(4,7$, and 21 excluded).

Bartlett's test of sphericity was significant $\left(\chi_{2}=1525.4, p<.001\right)$, indicating that EFA was appropriate. Multicollinearity was raised as a potential issue as the determinant was 0.000009985 and just below the cut off of 0.00001. Sample sizes of 100-200 are appropriate if communalities are > 0.5 (MacCallum et al. 1999). Although the current sample size for the EFA was 129 and some communalities were $<0.5$, the Kaiser-Meyer-Olkin (KMO) statistic was 0.912 , suggesting good adequacy of the sample size to determine distinct and reliable factors (Field 2005). Using the Kaiser-Guttman criterion of keeping factors with an eigenvalue $>1$ supports the choice for a 4-factor model. Yet, the scree plot did not support this choice indicating a 1-factor solution as more likely. Parallel analysis was undertaken to explore this issue further as it determines eigenvalues that are greater than chance (Wilson \& Cooper 2008; Zwick \& Velicer 1986). It supported the choice for a 1-factor solution. This constituted model 1 for the CFA.

\section{Confirmatory Factor Analysis}

Four models in total (see Table 1 for the specifications) were tested on sample 2 in terms of their fit with the data. The sample consisted of 624 participants from organisation C, reduced from the sample of 633 by 9 who had missing values on all variables. Model 3 was tested due to face validity suggesting that the item content in item 9 was more aligned with factor 1 than 2 . Model fit is presented in Table 2. 
Table 1. Outline of number of items and factor structure of the models to be tested

\begin{tabular}{|c|c|c|}
\hline & Number of items & Factors: items \\
\hline Model 1 (EFA) & 21 & 1: all except $4,7,21$ \\
\hline \multirow[t]{4}{*}{ Model 2 (theoretical) } & 24 & $1: 1-6$ \\
\hline & & 2: 7-12 \\
\hline & & 3: $13-17$ \\
\hline & & 4: $18-24$ \\
\hline \multirow[t]{4}{*}{ Model 3 (theory, 3 items excluded: 47 21) } & 21 & $1: 12356$ \\
\hline & & 2: 89101112 \\
\hline & & 3: 1314151617 \\
\hline & & 4: 181920222324 \\
\hline \multirow[t]{4}{*}{ Model 4 (theory, 3 items excluded, item 9 moved to } & 21 & 1:123569 \\
\hline & & 2: 8101112 \\
\hline & & 3: 1314151617 \\
\hline & & 4: 181920222324 \\
\hline
\end{tabular}


Table 2. Model fit statistics of all four models, with adjustments for models 3 and 4

\begin{tabular}{|c|c|c|c|c|c|c|c|c|}
\hline Model & $\chi^{2}$ (df) & FP & CFI & TLI & $\begin{array}{l}\text { RMSEA } \\
(90 \% \mathrm{CI})\end{array}$ & SRMR & AIC & BIC / ssaBIC \\
\hline 1 & $\begin{array}{l}834.042 * \\
(189)\end{array}$ & 63 & 0.865 & 0.850 & $\begin{array}{l}0.074 \mathrm{a} \\
(0.069-0.079)\end{array}$ & 0.049 & 32041.31 & $\begin{array}{l}32320.77 / \\
32120.76\end{array}$ \\
\hline 2 & $\begin{array}{l}1147.431 * \\
(246)\end{array}$ & 78 & 0.837 & 0.818 & $\begin{array}{l}0.077 \mathrm{a} \\
(0.072-0.081)\end{array}$ & 0.049 & 36574.43 & $\begin{array}{l}36920.45 / \\
36672.81\end{array}$ \\
\hline 3 & $\begin{array}{l}646.596 * \\
(183)\end{array}$ & 69 & 0.903 & 0.888 & $\begin{array}{l}0.064 \mathrm{a} \\
(0.058-0.069)\end{array}$ & 0.041 & 31865.85 & $\begin{array}{l}32171.94 / \\
31952.88\end{array}$ \\
\hline 4 & $\begin{array}{l}644.699 * \\
(183)\end{array}$ & 69 & 0.903 & 0.889 & $\begin{array}{l}0.064 \mathrm{a} \\
(0.058-0.069)\end{array}$ & 0.043 & 31863.95 & $\begin{array}{l}32170.05 / \\
31950.98\end{array}$ \\
\hline
\end{tabular}

Notes. $*$ all $\mathrm{p} \leq .001 ; \mathrm{FP}=$ free parameters; a Probability that $\mathrm{RMSEA} \leq .05 ; \mathrm{AIC}=$ Akaike Information Criterion; BIC = Bayesian Information Criterion; ssa = Sample-Size Adjusted; CFI = comparative fit index; TLI $=$ Tucker - Lewis index; RMSEA = Root Mean Square Error of Approximation; SRMR = Standardised Root Mean Square Residual.

Both Models 3 and 4 fit the data well. While neither model achieved a non-significant $\chi_{2}$, it needs to be noted that the $\chi_{2}$ test of model fit rejects well-fitting models in large samples, as statistical power to detect very small discrepancies between data and model increases (Gerbing \& Anderson 1985; Kline 2004). In terms of CFI and TLI, neither model achieved the cut-off of .95 , but CFI values were $>.90$. For both models the RMSEA did not achieve $>.05$, however the upper confidence interval was $<.08$. For both models the SRMR is <.08. The modification indices of both models highlighted that items 13 and 14, and items 18 and 19 should include correlated error terms (indicating non-independent errors). This led to the exclusion of items 13 and 18 (as informal inspection of the items suggested they were harder to understand than items 14 and 19). The two models were re-run without 13 and 18 (see Table 3: Models 3a and 4a). Finally, a superordinate factor Workplace Innovation was also tested (see Table 3: Model 3a SO and 4a SO). 
Table 3. Model fit statistics of models 3 and 4 with adjustments

\begin{tabular}{|c|c|c|c|c|c|c|c|c|}
\hline Model & $\chi_{2}(\mathrm{df})$ & $\mathbf{F P}$ & CFI & TLI & RMSEA (90\% CI) & $\begin{array}{l}\text { SRM } \\
\mathbf{R}\end{array}$ & AIC & BIC / ssaBIC \\
\hline $3 a$ & $\begin{array}{l}366.514 * \\
(146)\end{array}$ & 63 & 0.942 & 0.932 & $0.049 \mathrm{~b}(0.043-0.056)$ & 0.037 & 29299.14 & $\begin{array}{l}29578.62 / \\
29378.60\end{array}$ \\
\hline $4 a$ & $\begin{array}{l}366.495 * \\
(146)\end{array}$ & 63 & 0.942 & 0.932 & $0.049 \mathrm{~b}(0.043-0.056)$ & 0.040 & 29299.12 & $\begin{array}{l}29578.60 / \\
29378.58\end{array}$ \\
\hline 3a SO & $\begin{array}{l}3953.932 * \\
(171)\end{array}$ & 61 & 0.937 & 0.927 & $0.051 \mathrm{~b}(0.045-0.057)$ & 0.039 & 29316.49 & $\begin{array}{l}29587.10 / \\
29393.43\end{array}$ \\
\hline 4a SO & $\begin{array}{l}389.360 * \\
(148)\end{array}$ & 61 & 0.936 & 0.926 & $0.051 \mathrm{~b}(0.045-0.057)$ & 0.041 & 29317.99 & $\begin{array}{l}29588.59 / \\
29394.93\end{array}$ \\
\hline
\end{tabular}

Notes. $* \mathrm{p} \leq .05, * * \mathrm{p} \leq .01, * * * \mathrm{p} \leq .001 ; \mathrm{n} . \mathrm{s} .=$ non-significant; $\mathrm{FP}=$ free parameters; $\mathrm{b}$ Probability that RMSEA > .05; AIC = Akaike Information Criterion; BIC = Bayesian Information Criterion; ssa = Sample-Size Adjusted; CFI = comparative fit index; TLI = Tucker - Lewis index; RMSEA = Root Mean Square Error of Approximation; SRMR = Standardised Root Mean Square Residual.

All adjustments to Models 3 and 4 fit the data well. None of the $\chi^{2}$ values was non-significant but all RMSEA values were $<.05$ (other than the superordinate models with values of .051 ), with all upper limits for both models $<.08$. For all models the TLI and CFI were close to the .95 cut-off suggesting a good fit. The SRMR was below .08, with Model 3a achieving a slightly lower value than Model 4a. Although all models provided statistical fit to the data, Model 4a SO was chosen based on its theoretical underpinnings. Figure 1 presents the standardised loadings. 


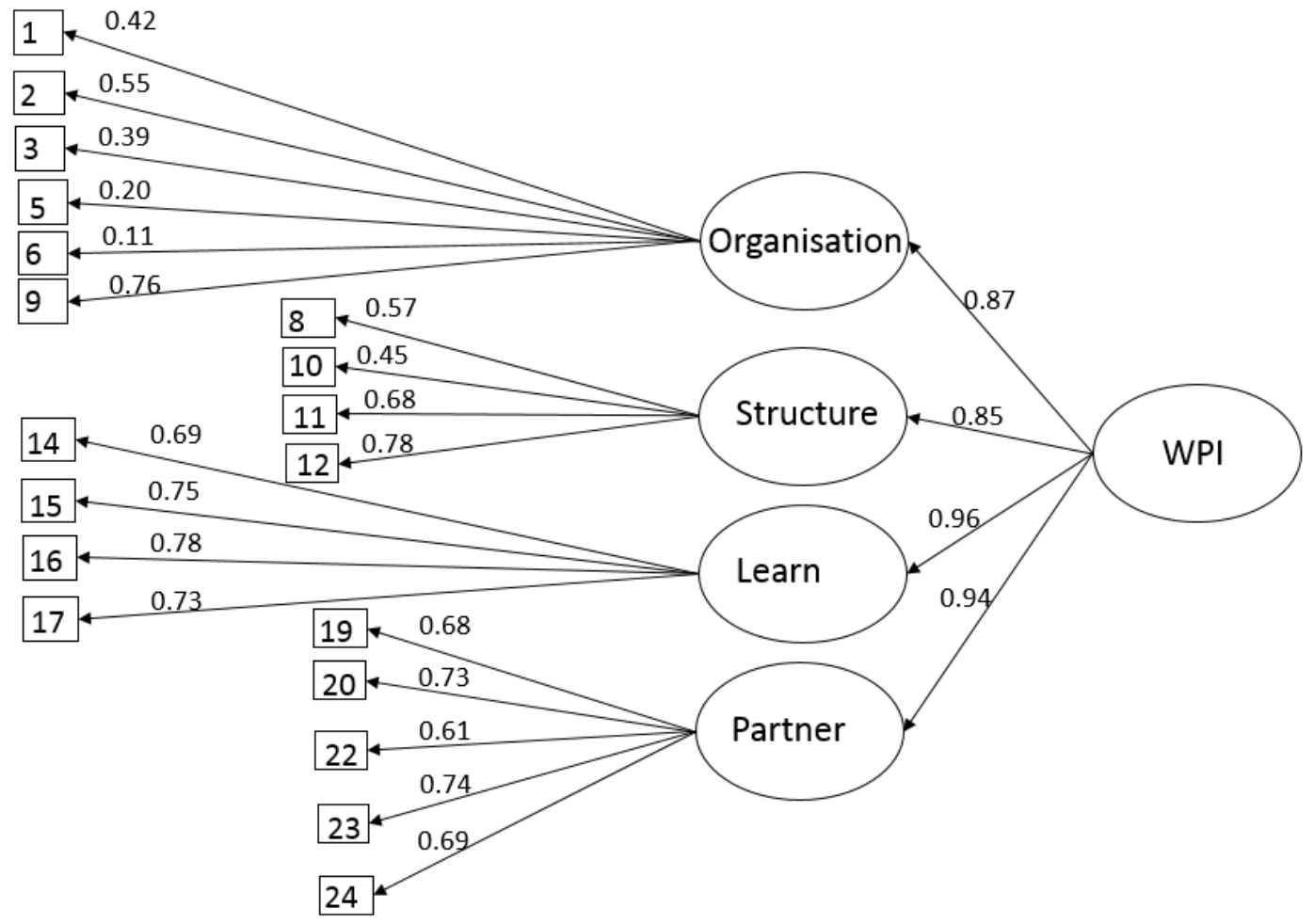

Figure 1. Standardised factor loadings for model 4a SO

\section{Validity analysis}

We hypothesized that WI practices would be positively associated with work engagement and job satisfaction, controlling for demographic variables. This was tested using the overall sample $(N=820$, with 35 excluded due to missing values). The overall model fit adequately: while the model fit was significant, $\chi_{2}(308)=613.3^{*}, p<.00001$, RMSEA and the upper limit of its confidence interval were below .05, RMSEA $=.035,90 \%$ CI $[.031, .039]$, while CFI and TLI were both < .95 (.905 and .894 respectively). The weighted root mean square residual was, however, slightly over the cut-off value of $<1$ (WRMR $=1.10)$. The standardised estimates are shown in Figure 2 (only significant paths are shown). 


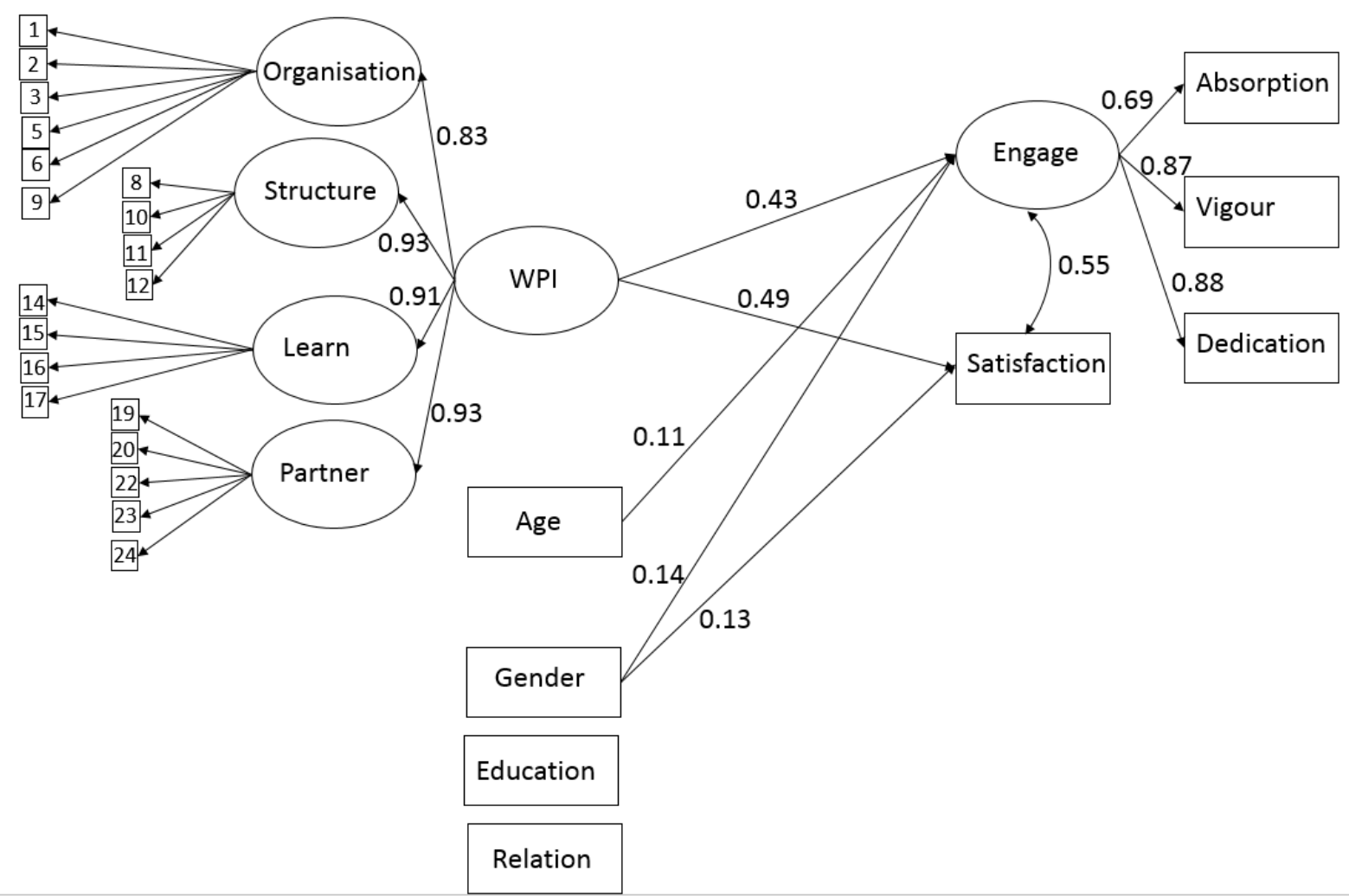

Figure 2. Overall model for the validation of WI with standardised estimates (Note: Gender was coded as $1=$ male, $2=$ female

Neither relationship status nor education level were significantly linked to work engagement or job satisfaction. Controlling for the significant effects of age and gender (work engagement and job satisfaction were higher for women), WI positively predicted both work engagement, $\beta=433,95 \% \mathrm{CI}$ $[.37, .50]$, and job satisfaction, $\beta=.487,95 \% \mathrm{CI}[.41, .57]$. Both were also significantly correlated with each other, $r=.55,95 \%$ CI $[.50, .60]$. Appendix 2 shows standardised estimates, standard errors, and $p$ values.

\section{Discussion}

The present study reports the evaluation and refinement of a measure for workplace innovation (WI) practices. The measure was based on a model of WI which has been widely used in practice for reflection and as a way to encourage consultation among stakeholders. For the original 24 -item version of the measure confirmatory factor analysis indicated poor reliability and no clear factor structure. However, attending to problems with individual items (e.g., removing redundant items and poorly performing items) improved both the reliability of measurements and produced a clearer factor structure. The final model that emerged from a confirmatory factor analysis was based on a 19-item scale had RMSEA, SRMR and TLI fit indices suggesting good to excellent fit. This model included four factors: jobs and teams (organization), structure, management and procedures (structure), employee involvement and innovation (learning), and shared leadership and voice (partnership). The refined version of the measure of the WI practices provides reliable assessment of four facets of WI practices. These factors have good face validity and, as expected, are predictive of both work engagement and job satisfaction. This new measure of WI practices therefore has the potential to be an important tool in increasing the reliability of future research on workplace innovation. 
While developments in our ability to measure WI practices are important, it is also important to consider the role of such measurement instruments in the context of the broader debate on the nature of WI. WI is not a checklist of practices but is an inherently social process (Dortmund Brussels position paper on WI 2012; Totterdill, Exton, Exton, \& Gold 2012) and demanding in terms of an integrated and successful implementation (Karanika-Murray \& Oeij 2017a, 2017b). It involves building skills and competence through creative collaboration and participatory practices grounded in continuing reflection, learning and improvement, which sustain the process of innovation in management, work organisation, and the deployment of technologies. The measure presented in this paper is the starting point to identifying the practices that can support true WI by helping practitioners and researchers to provide rigorous evidence for relevant practice and communicating WI to diverse groups of stakeholders with different agendas and understandings (Karanika-Murray \& Oeij 2017).

Measuring WI practices at the individual level has inherent limitations. First, these measures - in common with other scales -capture a subjective snapshot of how people view general characteristics of WI practices. This is both a strength (in not tying responses to particular organisation contexts or interventions) and a weakness (in not identifying the practices in question). This limitation can in principle be overcome by combining measurement of WI practices with observation or other qualitative data that captures or documents these practices. Second, individual measures may not fully capture WI at a team or organisation level. It is therefore sensible to consider using WI practices alongside measures at other levels and in combination with team or organisation measures such as climate. Methods also exist to simultaneously model individual and team effects of predictors such as WI practices within the same model (e.g., Enders \& Tofighi 2007). Put simply, a single measure such WI practices will not capture everything that researchers mean by the complex concept and process of WI, but nevertheless offers needed progress in capturing key aspects of WI.

Future research on WI is required to assess the potential contribution of WI practices and how best to combine WI practices with other sources of data. For example, in diagnosing the conditions that can lead to actionable solutions, individuals' perceptions of their ideal situation may be as important as their perceptions of the current situation. Present practice sometimes uses a "current minus ideal" combination in which the gap between current and ideal experiences of WI is used to guide interventions (Totterdill 2015). Although a universal benchmark of what is considered good WI can inform general guidance and recommendations, for the measure to be of further practical use it may be useful to take into account the preferences of employees on the ideal situation. The refined WI practices scale we propose here would facilitate such a comparison by ensuring more reliable estimation of the current situation. Additionally, the WI practices scale would also benefit from further evidence of external validity, for example through links to "hard" outcomes such as sickness absenteeism, turnover, early retirement, or performance.

\section{Conclusions}

This study offers a succinct, useful, and practical way to assess WI practices. We examined the psychometric properties of a 19-item climate measure and its dimensionality, by employing exploratory and confirmatory factor analyses, and offered evidence for its predictive validity in relation to employee engagement and job satisfaction. Constructing a valid and reliable measure of WI practices is an important first step in the evaluation of WI efforts. We hope that this new WI measure will encourage further research on understanding WI and its role in promoting healthy and productive workplaces. 


\section{References}

Bakker, A. B., \& Demerouti, E. (2007). The job demands-resources model: State of the art. Journal of managerial psychology, 22(3), 309-328.

Boud, D., Keogh, R., \& Walker, D. (1985). Reflection: Turning Experience into Learning. London: Kogan Page.

Boxall, P. and Purcell, J. (2003). Strategy and Human Resource Management. Palgrave Macmillan, Basingstoke.

Brödner, P. and Latniak, E. (2002), Sources of innovation and competitiveness: national programmes supporting the development of work organisation. Final Report to DG Employment and Social Affairs, Institute for Work and Technology, Gelsenkirchen.

Buchanan D. A. and Preston, D. (1992) Life in the cell: supervision and teamwork in a "manufacturing systems engineering" environment. Human Resource Management Journal, 2 (4) $55-80$

Business Decisions Limited, 2002. Benchmarking the Competitiveness of the European Animal Health Industry. A Report by Business Decisions Limited for FEDESA. BDL, UK.

CEDEFOP (2015), Skill shortages and gaps in European enterprises. Striking a balance between vocational education and training and the labour market, Luxembourg: Publications Office of the European Union, n.102. Available at: http://www.cedefop.europa.eu/it/publicationsandresources/publications/3071

Chan, D. (1998). Functional relations among constructs in the same content domain at different levels of analysis: A typology of composition models. Journal of Applied Psychology, 83(2), 234.

Christian, M. S., Garza, A. S., \& Slaughter, J. E. (2011). Work engagement: A quantitative review and test of its relations with task and contextual performance. Personnel Psychology, 64(1), $89-136$.

Dhondt, S., M. van Gramberen, F. Keuken, F. Pot, P. Totterdill \& F. Vaas (2011) Workplace innovation, Social Innovation Europe launch event. Nottingham: UKWON.

Dortmund Brussels Position Paper on Workplace Innovation (2012). (available at: http://ec.europa.eu/enterprise/policies/innovation/files/dortmund-brusselsposition-paperworkplace-innovation_en.pdf)

Eeckelaert, L., Dhondt, S., Oeij, P., Pot, F., Nicolescu, G.I., Trifu, A. \& Webster, J. (2012). Review of Workplace Innovation and Its Relation with Occupational Safety and Health: Literature Review. Bilbao, Spain: European Agency for Safety and Health at Work. (available at: https://osha.europa.eu/en/tools-and-publications/publications/reports/workplace-innovationreview).

EESC - European Economic and Social Committee (2011). Innovative workplaces as a source of productivity and quality jobs, (SC/034) Brussels.

Enders, C. K., \& Tofighi, D. (2007). Centering predictor variables in cross-sectional multilevel models: a new look at an old issue. Psychological Methods, 12(2), 121.

EIS (2014) - Exploratory Report on Workplace Innovation. (available at: https://www.zsi.at/object/project/2902/attach/2014_1013_EIS_Workplace_Innovation_EN.pd f)

Exton, R., \& Totterdill, P. (2009). Workplace innovation: bridging knowledge and practice. $A i$ \& Society, 23(1), 3-15.

Field, A. (2013). Discovering Statistics Using IBM SPSS Statistics. Sage publications.

Fried, Y., \& Ferris, G. R. (1987). The validity of the job characteristics model: A review and metaanalysis. Personnel Psychology, 40(2), 287-322.

Gerbing, D. W., \& Anderson, J. C. (1985). The effects of sampling error and model characteristics on parameter estimation for maximum likelihood confirmatory factor analysis. Multivariate Behavioral Research, 20, 255-271. 
Gkiontsi, D., \& Karanika-Murray, M. (2016). Dealing with economic and demographic challenges: Workplace innovation practices as a timely and effective response to older workers' needs. European Journal of Workplace Innovation, 2(1), 25-42.

Gustavsen, B. (1992), Dialogue and Development. Van Gorcum: Assen/Maastricht.

Hackman, J. R., \& Oldham, G. R. (1980). Work redesign. Reading: Alisson-Wesley.

Hu, L. T., \& Bentler, P. M. (1999). Cutoff criteria for fit indexes in covariance structure analysis: Conventional criteria versus new alternatives. Structural equation modeling: a multidisciplinary journal, 6(1), 1-55.

Humphrey, S. E., Nahrgang, J. D., \& Morgeson, F. P. (2007). Integrating motivational, social, and contextual work design features: a meta-analytic summary and theoretical extension of the work design literature. Journal of Applied Psychology, 92(5), 1332.

Huselid, M. A., Jackson, S. E., \& Schuler, R. S. (1997). Technical and strategic human resources management effectiveness as determinants of firm performance. Academy of Management journal, 40(1), 171-188.

Jansen, J., Volberda, H., \& van den Bosch, F. (2009). Erasmus Concurrentie en Innovatie Monitor 2008-2009 (Erasmus Competition and Innovation Monitor 2008-2009). Eindrapport (Final Report), Rotterdam School of Management, Rotterdam.

Karasek, R.A. and Theorell, T., Healthy work; stress, productivity and the reconstruction of working life. Basic Books, New York, 1990.

Karanika-Murray, M., \& Oeij, P.R.A. (2017a). How can work and organizational psychologists fortify the practice of workplace innovation? In: P.R.A. Oeij, D. Rus, \& F. Pot (Eds.), Workplace Innovation: Theory, Research and Practice, Heidelberg: Springer Publishing.

Karanika-Murray, M., \& Oeij, P.R.A. (2017b). The role of work and organizational psychology for workplace innovation: Fortifying practice. European Work \& Organizational Psychology-In Practice (special issue on Workplace Innovation). http://www.eawop.org/latest-issue

Kline, R.B. (2004). Beyond Significance Testing: Reforming Data Analysis Methods in Behavioral Research. Washington D.C.: American Psychological Association.

Lado, A. A., \& Wilson, M. C. (1994). Human resource systems and sustained competitive advantage: A competency-based perspective. Academy of management review, 19(4), 699-727.

MacCallum, R. C., Widaman, K. F., Zhang, S., \& Hong, S. (1999). Sample size in factor analysis. Psychological Methods, 4(1), 84.

MacLeod, D., \& Clarke N. (2009). Engaging for Success: Enhancing performance through employee engagement. London: BIS.

Morgeson, F. P., \& Humphrey, S. E. (2008). Job and team design: Toward a more integrative conceptualization of work design. Research in personnel and human resources management, 27,39 .

Muthén, L. K., \& Muthén, B. O. (1998-2014). Mplus User's Guide. Seventh Edition. Los Angeles, CA: Muthén \& Muthén.

OECD. Centre for Educational Research and Innovation (CERI). (2010). Innovative workplaces: making better use of skills within organisations. OECD, Paris, France.

Oeij, P.R.A., Rus, D., \& Pot, P. (2017). Workplace Innovation: Theory, Research and Practice (Eds.) Springer.

Oeij, P. R. A., Žiauberytė-Jakštienè, R., Dhondt, S., Corral, A., Totterdill, P., \& Preenen, P. (2015). Workplace Innovation in European companies. Study commissioned by Eurofound. Luxemburg: Office for Official Publications of the European Communities.

Parent-Thirion, A., Vermeylen, G., \& Houten, G. V. (2012). Eurofound (2012), Fifth European Working Conditions Survey. Publications Office of the European Union, Luxembourg, S, 158.

Pot, F.D. (2011). Workplace innovation for better jobs and performance. International Journal of Productivity and Performance Management, 60 (4), 404-415.

Pot, F., Dhondt, S., \& Oeij, P. (2012). Social innovation of work and employment. In Challenge Social Innovation (pp. 261-274). Springer Berlin Heidelberg.

Pot, F., Totterdill, P., \& Dhondt, S. (2016). Workplace innovation: European policy and theoretical foundation. World Review of Entrepreneurship, Management and Sustainable Development, 12(1), 13-32. 
Purcell, J., \& Georgiadis, K. (2007). Why should employers bother with worker voice?. What Workers Say: Employee Voice in the Anglo-American Workplace, 181-197.

Ramstad, E. (2009), Promoting performance and the quality of working life simultaneously. International Journal of Productivity and Performance Management, 58 (5), 423-436.

Ramstad, E. (2014). Can high-involvement innovation practices improve productivity and quality of working-life simultaneously? Management and employee views on comparisons. Nordic Journal of Working Life Studies, 4(4), 25-45.

Shantz, A., Alfes, K., Truss, C., \& Soane, E. (2013). The role of employee engagement in the relationship between job design and task performance, citizenship and deviant behaviours. The International Journal of Human Resource Management, 24(13), 2608-2627.

Schaufeli, W.B., Bakker, A.B., \& Salanova, M. (2006). The measurement of work engagement with a short questionnaire. Educational \& Psychological Measurement, 66(4), 701-716.

Teague, P. (2005) What is Enterprise Partnership? Organization, 12(4), 567-589.

Tidd, J. and Bessant, J., (2009), Managing Innovation: Integrating Technological, Market and Organizational Change, 4th edition, Chichester: John Wiley and Sons.

Totterdill, P. (2015) Closing the Gap: The Fifth Element and Workplace Innovation. European Journal of Workplace Innovation, 1(1). (available at http://journal.uia.no/index.php/EJWJ/article/view/166)

Totterdill, P., Dhondt, S., \& Milsome, S. (2002). Partners at work. A report to Europe's policy makers and social partners. Report of the Hi-Res Project (The High Road concept as a Resource) funded by DG Research of the European Commission under the Competitive and Sustainable Growth: Accompanying Measures Programme.

Totterdill, P. Exton, R., Exton, O., and Gold, M. (2012). Closing the gap between evidence-based and common practice -Workplace innovation and public policy in Europe. Lifelong Learning in Europe. 4/2012. (available at: http://www.lline.fi/en/article/policy/totterdill/closing-the-gapbetween-evidencebased-and-common-practice-workplace-innovation-and-public-policy-ineurope)

Totterdill, P. (2013) Job Design. EUWIN Theme Paper. (available at http://uk.ukwon.eu/_literature_3809/Job_design, accessed 3rd June 2014).

Truss, K., Baron, A., Crawford, D., Debenham, T., Emmott, M., Harding, S., Longman, M., Murray, E., \& Totterdill, P. (2013). Job Design and Employee Engagement. (available at: http://engageforsuccess.org/wp-content/uploads/2015/10/Job-Design-and-EmployeeEngagement-Katie-Truss-et-al-11.pdf)

UK Commission for Employment and Skills (UKCES) (2009), “About the UK Commission for Employment and Skills”, UK Commission for Employment and Skills, London, available at: www.ukces.org.uk/Default.aspx?page=1 (accessed 5 February 2009).

van der Hauw, P. A., Pasaribu, M. N., \& van der Zeijden, P. T. (2009). Slimmer werken: gebruik, mogelijkheden en opbrengsten in de praktijk [Working smarter: application, opportunities and proceeds in practice]. Zoetermeer: EIM

Volberda, H., Jansen, J., Tempelaar, M., Heij, K. (2011). Monitoren van sociale innovatie: slimmer werken, dynamisch managen en flexibel organiseren. [Monitoring of social innovation: smarter work, dynamic management and flexible organising.] Tijdschrift voor HRM, 1, 85110.

Walker, A. (1997). Combating age barriers in employment: European research report. Eurofound.

West, M. (2012) Effective Teamwork: Practical Lessons from Organizational Research. Oxford: Blackwell.

West, M. A., \& Lyubovnikova, J. (2012). Real teams or pseudo teams? The changing landscape needs a better map. Industrial and Organizational Psychology, 5(1), 25-28.

Wilson, P., \& Cooper, C. (2008). Finding the magic number: Methods for determining the number of factors in exploratory factor analysis. The Psychologist, 21(10), 866-867.

Zwick, W.R., \& Velicer, W.F. (1986). Comparison of five rules for determining the number of components to retain. Psychological Bulletin, 99, 432-442. 


\begin{abstract}
About the authors
Dr Fraenze Kibowski is a Senior Lecturer at Nottingham Trent University, UK. Her research focus topic is trauma and psychosis. Her strong methods background means that she supports diverse projects. Her latest cited output is a "how-to" chapter for latent class and latent profile analysis, which is her most cited output.
\end{abstract}

Fraenze.Kibowski@ntu.ac.uk

Prof Thom Baguley is Professor of Occupational Psychology at Nottingham Trent University.

Dr Peter Totterdill is Director of Workplace Innovation Europe and Visiting Professor at Kingston University (UK) and Mykolas Romeris University (Lithuania).

Dr Maria Karanika-Murray is Associate Professor of Occupational Psychology at Nottingham Trent University. She has published on older workers and workplace innovation.

Appendix 1a. The original list of items

\title{
Jobs and Teams
}

1. In [organization] employees decide how they do their jobs

2. In [organization] employees share common tasks and goals and/or work in teams

3. The technology used helps employees do their work

4. Technology determines how the work is done in [organization]

5. Employees have a say in their own working times / working time schedule

6. The flexibility applied in [organization] is harmful to employees' health (Reversed)

9. Taking initiative as an employee is highly supported

Organizational structures, management and procedures

7. [organization] has many layers between top management and the frontline

8. If you need to talk to top management, they are highly accessible

10. Some employees are regularly favoured above others (Reversed)

11. People feel understood and accepted by each other

12. Employees in [organization] feel free to bring up problems and tough issues

Employee-driven improvement and innovation

13. Employees in this [organization] are always searching for fresh, new ways of looking at problems

14. Employees in [organization] cooperate to help develop and apply new ideas

15. There are real attempts to share information throughout the organization

16. [organization] learns from good practice elsewhere as a means of improving the way we do things

17. We regularly take time to figure out ways to improve our organization's work processes

Co-created leadership and employee voice

18. Employees develop and make recommendations on issues that affect our organization's work

19. Employees speak up with ideas for new ways of working or changes in procedures

20. Managers and employees actively discuss decisions about the present and future of [organization]

21. Employee representatives help to ensure that employees' voices are heard

22. Employee representatives work with management to improve working conditions

23. The expertise of frontline employees is considered important in making strategic decisions

24. Management uses informal ways of consulting with employees as well as formal approaches 
Appendix 1b. The final measure of Workplace Innovation Practices

\section{Jobs and Teams}

1. In [organization] employees decide how they do their jobs

2. In [organization] employees share common tasks and goals and/or work in teams

3. The technology used helps employees do their work

4. Employees have a say in their own working times / working time schedule

5. The flexibility applied in [organization] is harmful to employees' health (Reversed)

6. Taking initiative as an employee is highly supported

\section{Organizational structures, management and procedures}

1. If you need to talk to top management, they are highly accessible

2. Some employees are regularly favoured above others (Reversed)

3. People feel understood and accepted by each other

4. Employees in [organization] feel free to bring up problems and tough issues

\section{Employee-driven improvement and innovation}

1. Employees in [organization] cooperate to help develop and apply new ideas

2. There are real attempts to share information throughout the organization

3. [organization] learns from good practice elsewhere as a means of improving the way we do things

4. We regularly take time to figure out ways to improve our organization's work processes

\section{Co-created leadership and employee voice}

1. Employees speak up with ideas for new ways of working or changes in procedures

2. Managers and employees actively discuss decisions about the present and future of [organization]

3. Employee representatives work with management to improve working conditions

4. The expertise of frontline employees is considered important in making strategic decisions

5. Management uses informal ways of consulting with employees as well as formal approaches 
Appendix 2. Standardized estimates, standard errors and p-values for the validation model

\begin{tabular}{|c|c|c|c|c|}
\hline & Estimate/S.E. & P-Value & & Estimate/S.E. \\
\hline Significant structural paths: & & \multicolumn{3}{|c|}{ Organization by: } \\
\hline WI to Engagement & $0.433 / 0.032$ & 0.0001 & 1 & $0.478 / 0.032$ \\
\hline WI to Satisfaction & $0.487 / 0.040$ & 0.0001 & 2 & $0.611 / 0.027$ \\
\hline Age to Engagement & $0.010 / 0.004$ & 0.003 & 3 & $0.430 / 0.033$ \\
\hline Gender to Engagement & $0.315 / 0.082$ & 0.0001 & 5 & $0.338 / 0.036$ \\
\hline Gender to satisfaction & $0.289 / 0.099$ & 0.003 & 6 & $0.215 / 0.038$ \\
\hline Non-sign. structural paths: & & & 9 & $0.831 / 0.024$ \\
\hline Age to Satisfaction & $0.005 / 0.004$ & 0.266 & Struc & e by: \\
\hline Education to Engagement & $0.004 / 0.061$ & 0.945 & 8 & $0.585 / 0.030$ \\
\hline Education to Satisfaction & $-0.103 / 0.073$ & 0.158 & 10 & $0.451 / 0.033$ \\
\hline Relationship to Engagement & $0.004 / 0.096$ & 0.965 & 11 & $0.660 / 0.024$ \\
\hline Relationship to Satisfaction & $0.154 / 0.115$ & 0.180 & 12 & $0.780 / 0.022$ \\
\hline
\end{tabular}

\section{Learn by:}

\begin{tabular}{lccc}
\hline WI by: & & 14 & $0.739 / 0.021$ \\
\hline Organization & $0.834 / 0.023$ & 15 & $0.723 / 0.022$ \\
\hline Structure & $0.930 / 0.017$ & 16 & $0.755 / 0.020$ \\
\hline Learn & $0.906 / 0.017$ & 17 & $0.755 / 0.021$ \\
\hline Partner & $0.925 / 0.015$ & \multicolumn{2}{c}{ Partner by: }
\end{tabular}


EUROPEAN JOURNAL OF WORKPLACE INNOVATION

\begin{tabular}{lccc}
\hline Absorption & $0.694 / 0.032$ & 20 & $0.745 / 0.023$ \\
\hline Vigour & $0.873 / 0.026$ & 22 & $0.619 / 0.028$ \\
\hline Dedication & $0.882 / 0.026$ & 23 & $0.720 / 0.024$ \\
\hline & & & \\
\hline
\end{tabular}

Note: "By" denotes measurement model; all other $\mathrm{p}$ values $\mathrm{p}<0.0001$; 